\title{
Innovative X-ray control technology of high-voltage circuit breaker technical condition
}

\author{
Leonid Darian ${ }^{1, *}$, Pavel Golubev ${ }^{1}$, and Roman Obraztsov ${ }^{1}$ \\ ${ }^{1}$ Technical Inspection UES, JSC, 109240 Moscow, Russia
}

\begin{abstract}
The paper presents the results of practical application of an instrumentation and analytical system (IAS) for X-ray control of minimum oil and SF6 circuit breakers. The capabilities of IAS are described and the technology for its implementation is given. It is shown that the proposed technology makes it possible to control the contact group (moving and fixed contacts) and elements of the moving contact control system of circuit breakers without bus bar dismantling, oil drain and disassembly of the circuit breaker poles. The paper also presents the assessment of the reliability indicators of high-voltage circuit breakers, which confirms the prospects for introducing the developed X-ray inspection technology.
\end{abstract}

\section{Introduction}

More than four thousand VMT-110 minimum oil circuit breakers are operated at the power facilities of the Russian Federation. According to Technical Inspection UES, JSC, failure rate of these circuit breakers has amounted to 0.02151 per year since the beginning of 2014. This kind of reliability indicator is almost 2 times higher than that for 100-199 kV highvoltage circuit breakers operating abroad $(0.01251$ per year) [1]. To ensure the required operational reliability of any type of equipment, including the one considered in this paper, it is necessary to use new effective means and methods for monitoring their condition. Taking into account that equipment reliability indicators are also determined by the duration, including regular maintenance of equipment, the preferred control methods are those that take minimal time to prepare and carry out. From this point of view, remote diagnostic monitoring systems are most preferable if they provide a reliable assessment of all functional units of the equipment. To monitor the condition of minimum oil circuit breakers, it is often required to dismantle them, drain the oil and disassemble them with the involvement of specialized organizations. The exclusion of these measures will improve the efficiency of monitoring the technical condition while reducing labor costs [2].
The purpose of this work is to study the capability and evaluate the effectiveness of the application of X-ray control method for high-voltage equipment using the example of monitoring VMT-110 minimum oil circuit breakers at the operation site without dismantling and disassembling.

To achieve this goal, the tasks of determining the informativeness of the proposed technology and checking its feasibility in the field conditions were solved.

\section{X-ray control object - minimum oil circuit breaker}

The VMT-110 is a high-voltage circuit breaker in which transformer oil is an extinguishing medium (Fig. 1). The three poles of the circuit breaker are mounted on a common frame and are controlled by a single drive. The pole of the circuit breaker is an oil-filled column consisting of a support insulator 1, an arc-extinguishing device 2, moving contact control system 3 and heating devices 4 built into the control mechanism body. The arc-extinguishing device 2 consists of an arcing chamber 5 , a fixed contact 6 , a cap 7 , an insulator 8 , a current lead 9 and a moving contact 10 . The arcing chamber 5 is located inside a fiberglass cylinder 11 [3].

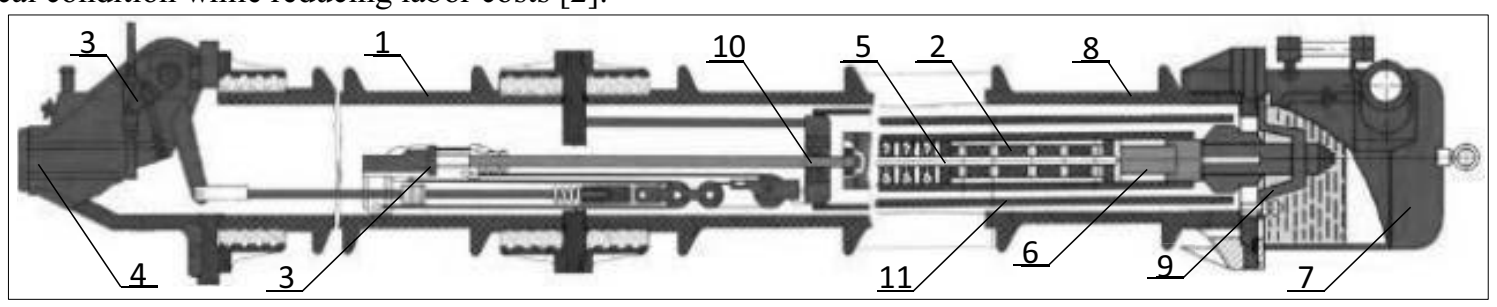

Fig. 1. VMT-110 circuit breaker pole section.

1 - support insulator; 2 - arc-extinguishing device; 3 - moving contact control system; 4 - heating device; 5 - arcing chamber; 6 - fixed contact; 7 - cap; 8 - insulator; 9 - current lead; 10 - moving contact; 11 - fiberglass cylinder.

\footnotetext{
* Corresponding author: leonid.darian $@$ gmail.com
} 
Despite the fact that the X-ray control method has recently begun to be actively used in the electric power industry [2, 4-8], the assessment of the high-voltage oilfilled equipment condition using X-ray images has not been carried out. Literature review showed that X-ray sources for monitoring the technical condition of electrical equipment are pulsed X-ray generators with a maximum cathode voltage from $75 \mathrm{kV}$ to $300 \mathrm{kV}$ or continuously operating units with a maximum cathode voltage of $300 \mathrm{kV}$, a maximum anode current of 3-7 mA and a focal spot diameter of $1.2-3 \mathrm{~mm}$ [9]. However, these sources cannot be used for X-ray inspection of high-voltage oil-filled equipment such as minimum oil circuit breakers.

To obtain informative images of the internal elements of heterogeneous structures with massive porcelain or polymer insulators, it is necessary to use specialized technical means and methods of X-ray control. A specialized instrumentation and analytical system (IAS) for X-ray examination of $110 \mathrm{kV}$ minimum oil circuit breakers has been currently developed in the Russian Federation [10]. IAS enables fast detection and visualization of most of the defects associated with a change in geometric dimensions of internal elements and assemblies, for example:

- deformation, wear, damage to the moving and fixed contacts;

- damage to cables, bearings and springs;

- displaced or missing structural elements.

At the same time, some of the operating defects of minimum oil circuit breakers, such as damage to drive parts outside insulators, manometers, oil indicators, etc., are available for visual inspection. And the electrical and speed characteristics of a circuit breaker can be monitored by existing diagnostic techniques.

\section{IAS for X-ray control of minimum oil circuit breakers}

The purpose of the developed system determined certain requirements for the X-ray unit to obtain informative Xray images of the internal elements of VMT-110 minimum oil circuit breakers. The source generates highenergy X-rays (up to $400 \mathrm{keV}$ ), contains the element filtering the radiation and has a small size of the X-ray tube focal spot $(\varnothing 1.5 \mathrm{~mm})$ [11]. This combination made it possible to significantly improve the visualization of minimum oil circuit breaker elements and assemblies on the X-ray image. In this case, the weight of the X-ray unit monoblock (radiation source) does not exceed $22 \mathrm{~kg}$.

The IAS positioning system is designed in such a way that two guides (one is with a radiation source and the other - with a receiver) are connected to each other and can be rotated around the circuit breaker pole to change the angle of X-ray imaging. The source and receiver are installed at the required height by using cables and winches, so that the output window of the radiation source is at the same level with the center of the receiver.

\section{Assessment of the informativeness of X-ray control method}

To assess the informativeness of X-ray imaging based on the analysis results of reasons for the failure of minimum oil circuit breakers in operation, a list of typical defects was formed (Table 1) and a special defective sample (SDS) was created on the basis of the VMT-110 minimum oil circuit breaker for laboratory researches.

Table 1. List of defects applied to SDS elements.

\begin{tabular}{|c|c|c|c|}
\hline Assembly & Element & Defect & No. \\
\hline \multirow{5}{*}{$\begin{array}{c}\text { Arc- } \\
\text { extinguishing } \\
\text { device }\end{array}$} & \multirow{4}{*}{$\begin{array}{l}\text { Moving } \\
\text { contact }\end{array}$} & $\begin{array}{c}\text { Contact rod } \\
\text { deformation (bend) }\end{array}$ & 1 \\
\hline & & $\begin{array}{l}\text { Worn-out contact } \\
\text { (decrease of diameter) }\end{array}$ & 2 \\
\hline & & Contact surface burn & 3 \\
\hline & & $\begin{array}{l}\text { Changes in contact } \\
\text { outer part height }\end{array}$ & 4 \\
\hline & $\begin{array}{l}\text { Fixed } \\
\text { contact }\end{array}$ & Cracks & 5 \\
\hline \multirow{6}{*}{$\begin{array}{l}\text { Moving } \\
\text { contact } \\
\text { control } \\
\text { system }\end{array}$} & \multirow{5}{*}{$\begin{array}{l}\text { Moving } \\
\text { contact } \\
\text { control } \\
\text { device }\end{array}$} & Damage to cable & 6 \\
\hline & & $\begin{array}{l}\text { Cable embedding } \\
\text { failure }\end{array}$ & 7 \\
\hline & & Damage to rollers & 8 \\
\hline & & $\begin{array}{c}\text { Bearings defect } \\
\text { (separators are absent) }\end{array}$ & 9 \\
\hline & & $\begin{array}{l}\text { Damage to upper } \\
\text { roller spring (block) }\end{array}$ & 10 \\
\hline & $\begin{array}{l}\text { Insulating } \\
\text { traction } \\
\text { rod }\end{array}$ & Cracks & 11 \\
\hline $\begin{array}{l}\text { Support } \\
\text { insulator }\end{array}$ & $\begin{array}{l}\text { Porcelain } \\
\text { cover }\end{array}$ & Cracks & 12 \\
\hline
\end{tabular}

Laboratory X-ray studies of the SDS were performed in a special room with walls, floor and ceiling absorbing radiation (Fig. 2a) in accordance with the layout of objects shown in Fig. 2b [12].

Some X-ray images obtained in laboratories are shown in Fig. 3. For example, the fixed contact (Fig. 3a) must be monitored for integrity and the absence of deformations and cracks on its casing. Visual inspection of the left, right and upper boundaries of the casing Xray images (Fig. 3b) shows that the vertical boundaries of the casing image have breaks and distortions (No. 1 and No. 2). That indicates a defect in the casing of the fixed contact. The upper boundary of the image is even and without breaks, therefore, defects are absent in this part of the SDS fixed contact, which fully corresponds to reality (Fig. 3a) [13].

One of the most common defects, for the detection of which it is necessary to monitor the moving contact (Fig. 3c), is a wear (decrease of diameter) as a result of the moving contact erosion during switching of a circuit breaker. Visual inspection of the left and right 


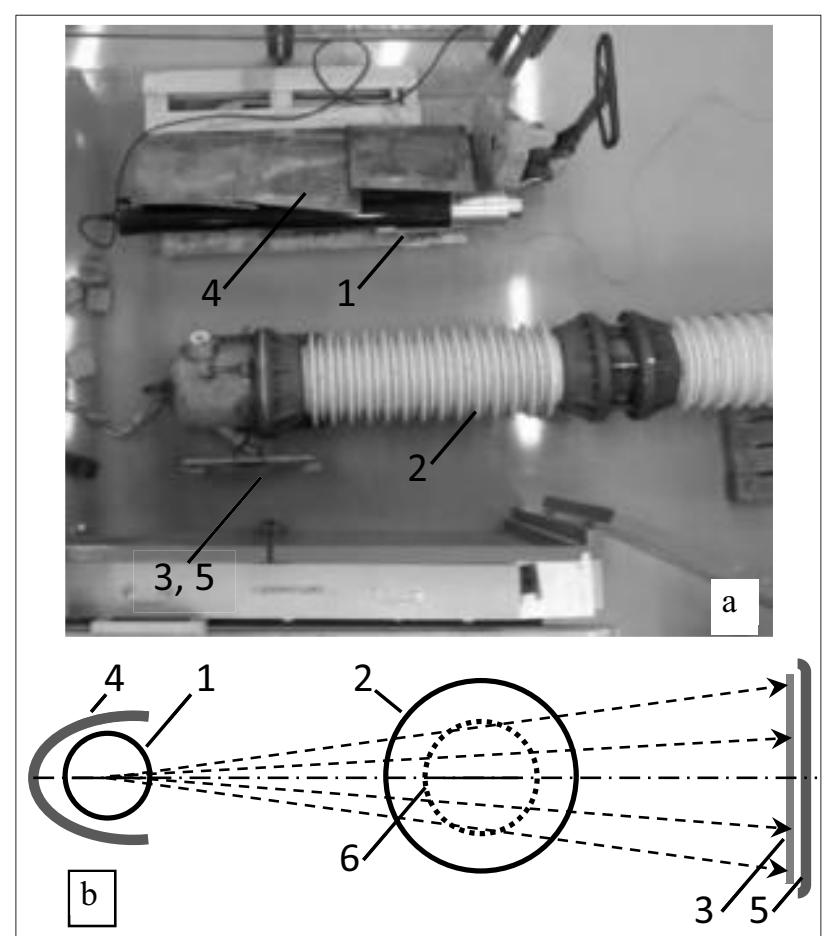

Fig. 2. Laboratory X-ray studies of the SDS (top view) (a) and the layout of objects (side view) (b).

1 - radiation source (X-ray unit monoblock); 2 - SDS; 3 - X-ray receiver (X-ray film); 4, 5- protection against backscattered radiation (lead plates); 6 - SDS examined zone.

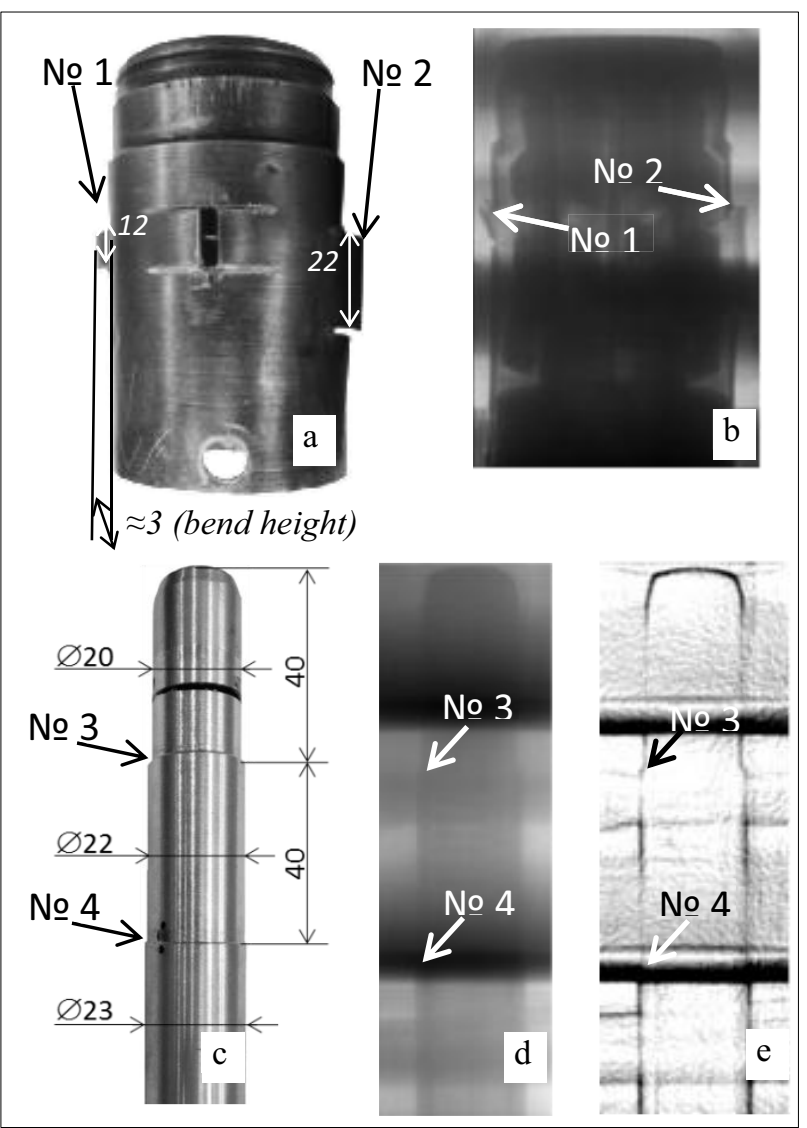

Fig. 3. Identification of defects of fixed (a) and moving (c) contacts based on their X-ray images before (b), (d) and after digital processing (e). boundaries of the X-ray images of the contact part (Fig. 3d, 3d) shows that the vertical boundaries of the image have "steps" (No. 3 and No. 4). Thus, the wear of the moving contact is revealed by the X-ray image (Fig. 3c).

The X-ray images of all SDS elements with applied defects obtained in two mutually perpendicular projections were analyzed in a similar way. The results of comparing the X-ray images of these elements with actual defects have shown that X-ray analysis can reveal 9 out of 12 simulated defects of VMT-110 circuit breaker internal structural elements. Thus, it can be stated that the X-ray control method makes it possible to reveal at least $75 \%$ of typical defects of VMT-110 internal elements.

Defects of the rollers of the moving contact control system (defect No. 8 in Table 1) were not revealed due to the small equivalent radiation thickness of the edges of the rollers made of aluminum alloy. For the same reason, no cracks were found on the fiberglass insulating rods (defect No. 11 in Table 1) and on the porcelain insulator (defect No. 12 in Table 1).

Despite the fact that the porcelain insulator and oil inside the SDS pole are sources of scattered radiation that "noises" the X-ray image and absorb part of X-ray radiation that carries useful information, the obtained $\mathrm{X}$ ray images allow us to unambiguously identify the internal structural elements of the circuit breaker and reveal most of the SDS defects [14]. In this case, the resolution of the obtained X-ray image of the equipment is not worse than $1 \mathrm{~mm}$ of its original size. This is confirmed, in particular, by the results of X-ray imaging of the contact part of the moving contact (Fig. 3e). To improve the quality of visualization of the SDS structural elements, the X-ray images were processed using modern digital technologies (binning, smoothing and differential filters) (Fig.3e).

\section{IAS operation in the field}

In order to test IAS, X-ray examinations of VMT-110 minimum oil circuit breakers were performed at four substations (Fig. 4). The results of the sequentially performed analysis and interpretation of five X-ray images of one of the VMT-110 poles obtained during the testing of the system will be further discussed [10].

Defects Nos. 1-4 (in accordance with Table 1) can be detected by two X-ray images at a $550 \mathrm{~mm}$ position upward from the central flange along the length of the pole (Fig. 4): across the frame (Fig. 5a) and along the frame (Fig. 5b) of the circuit breaker.

Analysis of the X-ray images in Fig. 5 shows: - no deviations from the conventional straight line of the longitudinal contours of the image of the moving contact rod were found. Defect No. 1 (deformation of the moving contact rod) was not detected;

- the transverse size of the image of the contact part of the moving contact is equal to the nominal transverse size of the image of the moving contact rod (outside the contact part). Defect No. 2 (wear of the moving contact (diameter decrease)) was not identified; 


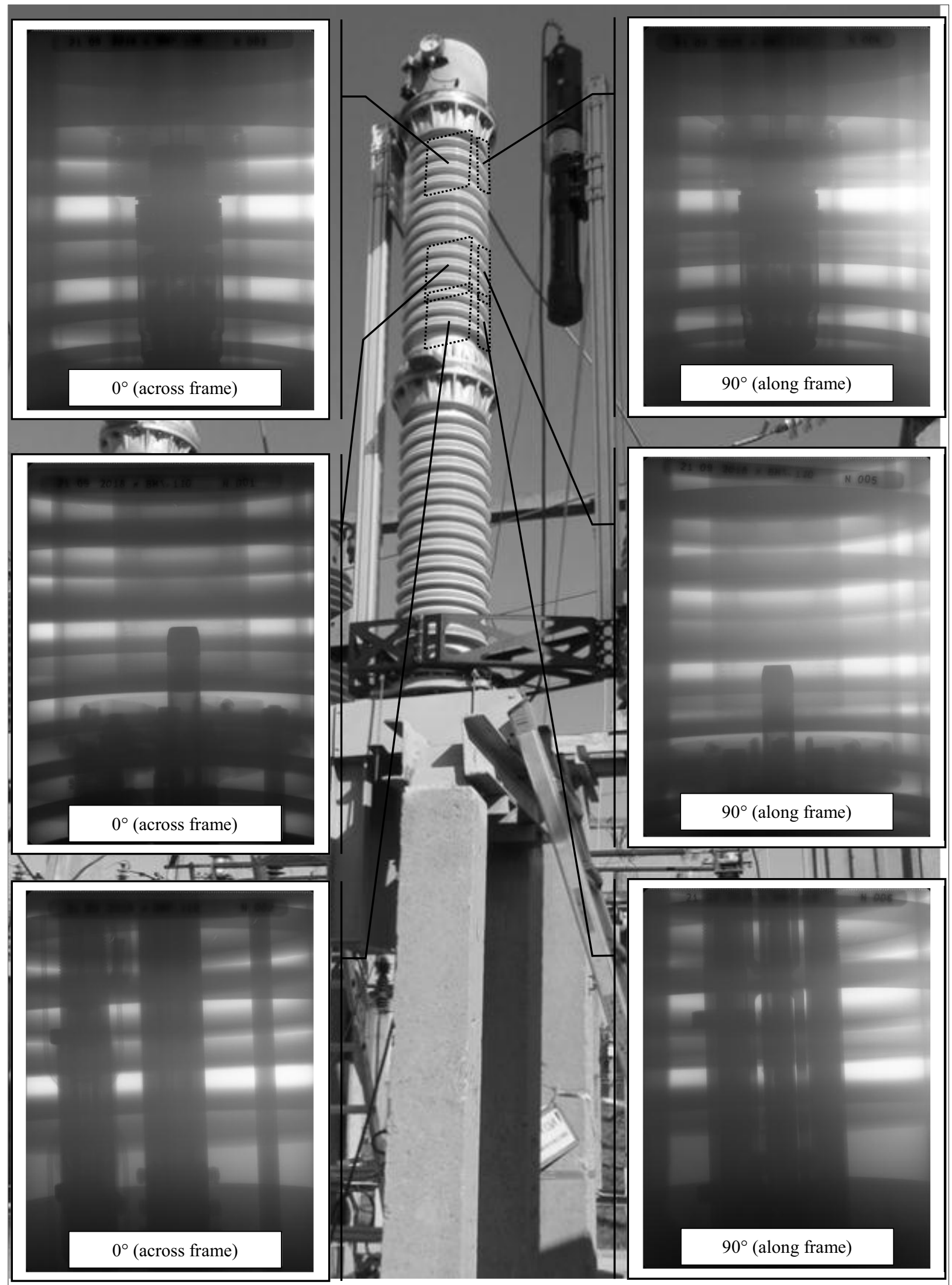

Fig. 4. X-ray system mounted on the circuit breaker and the obtained X-ray images [10].

- the transverse size of the image of the contact part of the moving contact is equal to the nominal transverse size of the image of the moving contact rod (outside the contact part) and there are no local deviations from the straight line of at least one of the longitudinal contours of the image of the contact part of the moving contact. Defect No. 3 (burn of the contact surface of the moving contact) was not revealed; 
- the longitudinal size of the image of the metallic and ceramic tip of the moving contact is not less than $17 \mathrm{~mm}$, which meets the requirements of the repair instructions for circuit breakers of this series. Defect No. 4 (height decrease of the outer part of the moving contact) was not identified.

Defect No. 5 (cracks on the casing of the fixed contact) can be detected by two X-ray images at a position $1000 \mathrm{~mm}$ upward from the central flange along the length of the pole (Fig. 4): across the frame (Fig. 6a) and along the frame (Fig. 6b) of the circuit breaker.

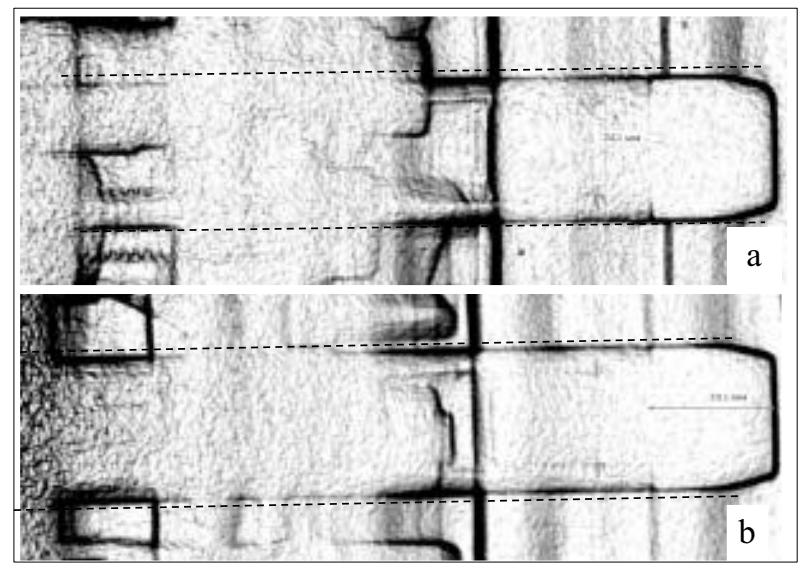

Fig. 5. Inspection of rod deformation, wear, contact surface burn, height decrease of contact part of moving contact (defects Nos. 1, 2, 3, 4) [10].

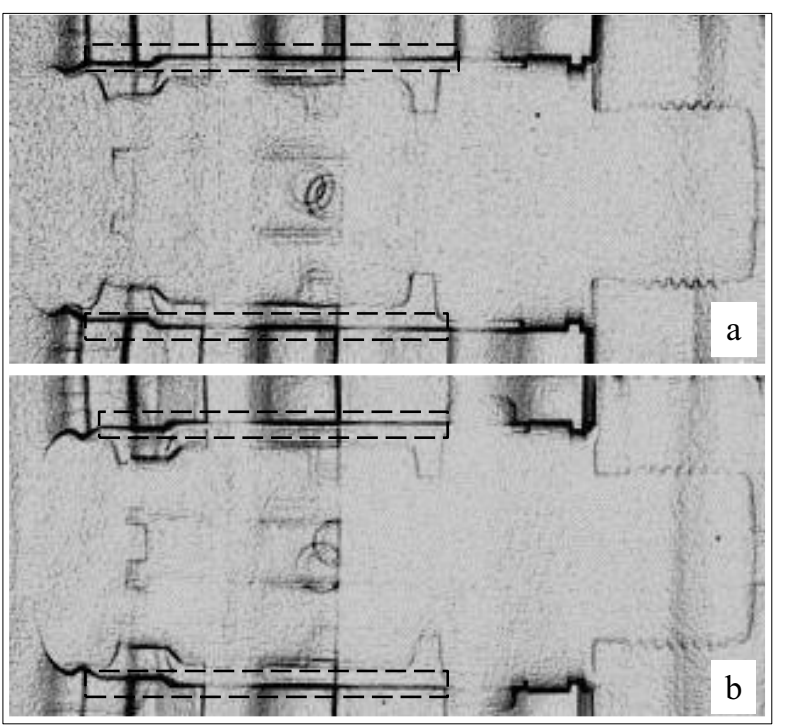

Fig. 6. Inspection of fixed contact casing (defect No. 5) [10].

According to the X-ray images in Fig. 6, no deviations from the straight line of at least one of the longitudinal contours of the image of the fixed contact casing were found. Also, no dark or light stripes that intersect the longitudinal contours of the image were found. Defect No. 5 was not identified.

The X-ray images of the rest elements obtained in two mutually perpendicular projections were analyzed in a similar way. The results of the analysis of the X-ray images made it possible to conclude that there was no damage to the contact group and moving contact control elements, as well as displaced or missing structural elements in the examined VMT-110 circuit breaker.

To conclude, according to our estimations based on the data analysis of VMT-110 circuit breakers failures since 2014, the use of the developed IAS will reduce the failure rate from 0.02151 per year to 0.01911 per year, which corresponds to a decrease in accidents by more than $10 \%$.

\section{Conclusions}

1. The innovative technology that allows to carry out a full cycle of X-ray inspection of minimum oil circuit breakers in the field conditions is presented. The possibility of detecting at least $75 \%$ of typical defects in internal elements of a minimum oil circuit breaker is shown.

2. Testing of the developed X-ray system was carried out at four $110 \mathrm{kV}$ substations with a positive result confirmed after dismantling minimum oil circuit breakers.

3. The assessments have shown that the introduction of the X-ray control method will improve the operational reliability of the inspected equipment a failure rate of VMT-110 minimum oil circuit breakers can be reduced by more than $10 \%$.

\section{References}

1. V.A. Nepomnyashchy, L.A. Darian, El. Eng. Lib., 9(237), 124 (2018) (in Russian)

2. J. Michaelson, ABB Library (2016)

3. IBKZH.674.143.001 TO (1989) (in Russian)

4. L.A. Darian, P.V. Golubev, R.M. Obraztsov et al., En.Exp., 3, 62-66 (2017) (in Russian)

5. J. Michaelson, A. Moglestue, T\&D World (2013)

6. A.H. Shinohara, D.M.F. Santana, P.P.J.C. Oliveira, DIR 2007 (2007)

7. I.V. Vaskin, A.A. Yakub, EEPIR, 3(42), 112-114 (2017) (in Russian)

8. X. Pang, Y. Qi, X. Li, H. Wu, H. Jing, Q. Xie. 2018 IEEE ICHVE (2018).

9. L.A. Darian, R.M. Obraztsov, En.Exp., 2(70), 48-55 (2019) (in Russian)

10. L.A. Darian, P.V. Golubev, R.M. Obraztsov et al., EEPIR, 1(52), 134-141 (2019) (in Russian)

11. L.A. Darian, P.V. Golubev, R.M. Obraztsov et al., Patent No. 189440 RU, (2019) (in Russian)

12. L.A. Darian, E.P. Grabchak, P.V. Golubev, R.M. Obraztsov, Int. Conf. of Doble Clients (2020).

13. L.A. Darian, E.P. Grabchak, R.M. Obraztsov, P.V. Golubev et al., El. Eng., 8, 36-41 (2020) (in Russian)

14. L.A. Darian, P.V. Golubev, R.M. Obraztsov, E.P. Grabchak et al., IEEE TDEI, 27(1), 172-180 (2020) 